\title{
Multiple global radiations in tadpole shrimps challenge the concept of 'living fossils'
}

'Living fossils', a phrase first coined by Darwin, are defined as species with limited recent diversification and high morphological stasis over long periods of evolutionary time. Morphological stasis, however, can potentially lead to diversification rates being underestimated. Notostraca, or tadpole shrimps, are an ancient, globally distributed order of branchiopod crustaceans regarded as 'living fossils' because their rich fossil record dates back to the early Devonian and their morphology is highly conserved. Recent phylogenetic reconstructions have shown a strong biogeographic signal, suggesting diversification due to continental breakup, and widespread cryptic speciation. However, morphological conservatism makes it difficult to place fossil taxa in a phylogenetic context. Here we reveal for the first time the timing and tempo of tadpole shrimp diversification by inferring a robust multilocus phylogeny of Branchiopoda and applying Bayesian divergence dating techniques using reliable fossil calibrations external to Notostraca. Our results suggest at least two bouts of global radiation in Notostraca, one of them recent, so questioning the validity of the 'living fossils' concept in groups where cryptic speciation is widespread. 
1 Thomas C. Mathers, School of Biological, Biomedical and Environmental Sciences,

2 University of Hull, Hull, HU6 7RX, UK

3 Robert L. Hammond, Department of Biology, University of Leicester, University Road,

$4 \quad$ Leicester, LE1 7RH, UK

5 Ronald A. Jenner, Life Sciences Department, The Natural History Museum, Cromwell Road,

6 London SW7 5BD, UK

7 Bernd Hänfling, School of Biological, Biomedical and Environmental Sciences, University

8 of Hull, Hull, HU6 7RX, UK

9 Africa Gómez School of Biological, Biomedical and Environmental Sciences, University of 10 Hull, Hull, HU6 7RX, UK

11

12 Corresponding author: Africa Gómez School of Biological, Biomedical and Environmental

13 Sciences, University of Hull, Hull, HU6 7RX, UK, tel: +44(0)1482465542, e-mail:

14 a.gomez@hull.ac.uk 
INTRODUCTION

17 There has been much debate about the tempo and mode of the diversification of life (Eldredge

18 \& Gould 1972; Reznick \& Ricklefs 2009; Rhodes 1983). Recently, this debate has been

19 informed by dating using relaxed molecular clocks and diversification analyses; techniques

20 which have revealed disparate patterns of speciation with early bursts (Burbrink \& Pyron

21 2010), recent radiations (Nagalingum et al. 2011) and density dependency (Phillimore \& Price

22 2008) being demonstrated. One extreme and often controversial pattern of diversification is

23 found in 'living fossils', a concept introduced by Charles Darwin in the Origin of Species

24 when dealing with the perplexing nature of the platypus and lungfish, relicts of once diverse

25 groups (Darwin 1859). Since Darwin's first use, the 'living fossil’ term has been applied to

26 groups which appear to have diversified little and are morphologically stable over long

27 periods of evolutionary time, with examples including cycads, tuatara, coelacanths, horseshoe

28 crabs and Ginkgo biloba. However, morphological stasis can obscure the patterns of species

29 diversification, and recent time-calibrated phylogenetic analysis of some 'living fossils' has

30 indeed revealed that extant species are in fact only recently diverged (Kano et al. 2012;

31 Nagalingum et al. 2011).

32 Notostraca, or tadpole shrimps, are an ancient, globally distributed order of branchiopod

33 crustaceans with a rich fossil record dating back to the early Devonian (Fayers \& Trewin

34 2002). The order has two extant genera, Triops and Lepidurus, in the family Triopsidae, with a

35 yet undefined number of species. The nomenclature and systematic position of some ancient

36 extinct Notostraca lineages, is, however, problematic (Hegna \& Dong 2010). Partly, this is

37 due to the fact that throughout their evolutionary history, tadpole shrimps have maintained an

38 extremely conserved yet complex bauplan with fossils indistinguishable from extant species

39 of Triops found as early as the Triassic (Gall \& Grauvogel-Stamm 2005; Gore 1986;

40 Trusheim 1938) and of Lepidurus in the Jurassic (Barnard 1929; Haughton 1924). This 
41 striking morphological conservatism has led them to be referred to as 'living fossils' (Fryer

42 1988; King \& Hanner 1998; Mantovani et al. 2008).

43 Phylogenetic reconstructions of extant Notostraca show a strong biogeographic signal

44 (Mathers et al. 2013; Vanschoenwinkel et al. 2012). In Triops, species complexes are largely

45 restricted to single continents, while Lepidurus lineages show high levels of endemism

46 (Rogers 2001), patterns that suggest ancient radiation with diversification through continental

47 break-up. However, the extreme morphological conservatism of this order hampers both the

48 taxonomy of extant species and the phylogenetic placement of fossil taxa, with little known

49 about the timing and tempo of notostracan diversification. Genetic analyses have revealed

50 widespread cryptic species (King \& Hanner 1998; Korn et al. 2010; $\underline{\text { Korn \& Hundsdoerfer }}$

51 2006; Macdonald et al. 2011; Vanschoenwinkel et al. 2012), further illustrating the difficulty

52 of inferring past and present diversity. To rectify this difficulty we infer a robust phylogeny of

53 all known notostracan species from both extant genera and seven branchiopod outgroups. Our

54 analysis uses all available Notostraca sequence data for seven genes, and Bayesian relaxed

55 clock dating techniques, with multiple branchiopod fossil calibrations, to estimate divergence

56 times.

\section{MATERIALS AND METHODS}

\section{Species delimitation}

59 As Notostraca is known to contain cryptic species complexes (eg. King \& Hanner 1998), and

60 in order to follow the same criterium for species selection for the multilocus analysis, we

61 delimited species using a generalised mixed Yule coalescent (GMYC) model (Pons et al.

$62 \underline{2006}$ ) fitted to an ultrametric phylogeny based on all available cytochrome oxidase I (COI)

63 sequences from GenBank. 270 sequences were aligned with Muscle (Edgar 2004) and

64 phylogeny estimated with BEAST v1.7.4 (Drummond et al. 2012) under a constant population 
65 size coalescent tree model and GTR $+\Gamma$ substitution model. A strict molecular clock was used

66 with the substitution rate fixed to 1 to provide branch lengths relative to an arbitrary time

67 scale. The MCMC chain was run for 9,000,000 iterations with the first 500,000 iterations

68 removed as burnin. Effective sample sizes (ESS's) of parameters (all greater than 200) and

69 appropriate burnin were checked using Tracer v1.5 (Rambaut \& Drummond 2007). From this

70 a maximum clade credibility tree using median heights was made. We then fitted a single

71 threshold GMYC model to the COI tree to delimit species from populations. A total of 34

72 species of Notostraca were identified in this analysis (Table S1).

\section{Multilocus phylogenetic analysis of Branchiopoda}

74 We constructed a multilocus alignment containing representatives of all known species of

75 Notostraca. Single representatives of each phylogenetic species identified by the GMYC

76 analysis were selected for inclusion in our phylogenetic analysis. In addition, four Notostraca

77 lineages (T. gadensis, T. cf. granarius Tunisia), L. bilobatus and L. cryptus) which did not

78 have COI data available but were represented by other genes, were also used in our multilocus

79 phylogenetic analysis. The species status of these lineages has been confirmed in regional

80 studies of cryptic diversity (King \& Hanner 1998; Korn et al. 2010; Korn \& Hundsdoerfer

81 2006; Rogers 2001). We also included seven representatives of the other branchiopod orders

82 so that robust fossil calibrations could be applied for the dating analysis. We included

83 sequences for the genes 12S, 16S, 28S, cytochrome oxidase I (COI), Elongation Factor

84 1-alpha (EF1), RNA Polymerase II and Glycogen Synthase (see Table S2 for Accession

85 Numbers).

86 Sequences were aligned using MUSCLE (Edgar 2004) with final adjustments by eye. Introns

87 in the nuclear protein coding genes were identified and removed based on alignment with

88 available Notostraca mRNAs. Translation was checked in MEGA 5 (Tamura et al. 2011).

89 Overall, sequences for 45 taxa (38 notostracan and 7 branchiopod outgroups) were 
90 concatenated for analysis with the alignment containing 5793 positions and $52 \%$ missing data

91 (Table S2; the alignment file is available in Dryad doi:xxxxxx).

92 Optimum partitioning schemes and substitution models for our phylogenetic analysis and

93 divergence time estimation were identified using PartitionFinder (Lanfear et al. 2012).

94 PartitionFinder uses a heuristic search algorithm, starting with a fully partitioned analysis

95 (gene and codon position where appropriate), and identifies the best fit partitioning scheme

96 and substitution models based on Bayesian Information Criterion (BIC). Due to the restricted

97 model choice available in RAxML we conducted separate PartitionFinder analyses for the

98 phylogenetic analysis and divergence time estimation. For the phylogenetic analysis we

99 restricted model choice options to GTR or GTR $+\Gamma$ whereas for divergence time estimation

100 we allowed models to be selected from the full suite available in BEAST. We excluded

101 models with proportion of invariant sites $(+\mathrm{I})$ as rate heterogeneity is accounted for by the

102 gamma shape parameter $(+\Gamma)$. Optimum partitioning schemes and substitution models for

103 both analyses are given in Tables S3 and S4.

104 Branchiopod phylogeny was estimated using Bayesian and maximum likelihood (ML)

105 methods with partitions and substitution models set to those identified by PartitionFinder

106 (Table S3). Bayesian analysis was performed with MrBayes v3.2 (․ㅡquist et al. 2012).

107 Model parameters between partitions were unlinked. Two independent MCMC chains were

108 run for $10,000,000$ iterations each, sampling every 5,000 iterations. The first $25 \%$ of each run

109 was discarded as burnin with the remaining samples pooled and used to create a maximum

110 clade credibility tree. Maximum likelihood phylogenetic analysis was performed using

111 RAxMLHPC-PTHREADS v7.0.4 (Stamatakis 2006). An initial ML search using GTR $+\Gamma_{4}$

112 was performed onto which 100 rapid bootstraps were drawn. 
114 We estimated Bayesian divergence times with BEAST v1.7.4 (Drummond et al. 2012) using

115 an uncorrelated lognormal relaxed clock (Drummond et al. 2006) and a Yule speciation prior.

116 XML files for all BEAST runs were created using BEAUTi v1.7.4 (Drummond et al. 2012).

117 Topology was constrained to that of the unconstrained RAxML analysis. We used the best fit

118 partitioning scheme identified by PartitionFinder (Table S4) and estimated substitution model

119 parameters independently for each partition. Initial runs were conducted using substitution

120 models identified by PartitionFinder, however, this resulted in poor mixing of some GTR

121 model parameters for partitions 1, 2 and 5, so subsequent runs were performed using a

122 simpler $\mathrm{HKY}+\Gamma$ model for these partitions.

123 Five branchiopod fossils representing the oldest known occurrences of their respective crown

124 groups were used to calibrate the molecular clock with minimum age constraints (Table 1).

125 Lognormal prior distributions were used to specify the level of uncertainty in the placement of 126 these fossil calibrations as they reflect the likely scenario that the true date of divergence of a 127 given node was some time before the earliest known fossil belonging to that clade ( $\underline{\text { Ho \& }}$ 128 Phillips 2009). Lognormal distributions have 3 parameters - mean, standard deviation and 129 offset. We set the offset to correspond to the minimum age of the node as determined by the 130 fossil record, we then specified mean and standard deviations that resulted in $95 \%$ of the 131 distribution falling between the age of the fossil and the age of the next oldest fossil (at a 132 lower taxonomic level) for that group. This gives a prior distribution, which assigns the 133 majority of the probability close to the age of the oldest known fossil but gives a long tail to 134 account for uncertainty in the proximity of the fossil to the true date of divergence. As 135 Bayesian divergence dating benefits from at least one maximum age constraint we 136 conservatively constrained the root of the tree to a maximum age of $558 \mathrm{Mya}$, the age of the 137 oldest Bilaterian fossil (Fedonkin et al. 2007). 
138 We ran two independent BEAST MCMC chains for 50,000,000 iterations, sampling every

1395000 iterations. 10,000,000 iterations were removed as burnin from each run. Convergence of

140 the two runs and the ESS of parameter estimates (all greater than 250) where assessed using

141 Tracer v1.5 (http://tree.bio.ed.ac.uk/software/tracer/). A posterior sample of 8000 trees from

142 one of the runs was used to construct a maximum clade credibility time tree for Notostraca

143 and our selected outgroups.

144 Diversification Analysis

145 Patterns of diversification through time within Notostraca were investigated using LASER

146 (Rabosky 2006) based on the BEAST time tree with outgroups pruned. Using LASER we

147 compared constant rate and variable rate speciation models using likelihood ratio tests (Table

148 S5).

\section{RESULTS AND DISCUSSION}

150 The most complete taxon sampling to date coupled with the inclusion of multiple nuclear and

151 mitochondrial markers allowed us to generate a robust phylogeny of 38 extant Notostraca

152 species. ML and Bayesian inference gave highly congruent phylogenetic trees with most

153 branches highly supported (Figures S1 and S2). The recovered relationships between

154 Branchiopod orders are in agreement with recently published Arthropod phylogenies (Regier

155 et al. 2010; von Reumont et al. 2012), providing a solid platform for divergence dating

156 analysis.

157 Our robust time-calibrated phylogeny of Branchiopoda (Figure 1) clearly shows that

158 Notostraca have a pattern of diversity incompatible with Darwin's original usage of the term

159 'living fossil' as relics of once diverse groups, and importantly reveals cryptic patterns of

160 diversification. Our analysis - using outgroup fossil calibrations - estimates an ancient

161 divergence of Triops and Lepidurus during the Jurassic, 184 Mya (95\% confidence interval 
162132 - 259 Mya), which agrees with the earliest fossils assigned to Lepidurus (Barnard 1929;

163 Gand et al. 1997), and with a sister relationship of Notostraca to the extinct order

164 Kazacharthra of the Late Triassic/Early Jurassic (Olesen 2009). The initial radiation of extant

165 Notostraca was not however, due to continental break up as the timing and pattern of

166 diversification within the genera substantially postdates the break-up of Pangaea 160 - 138

167 Mya (Scotese 2001). Furthermore, the current species distributions of Triops and Lepidurus

168 are likely to have resulted from a second global radiation of the order, possibly following

169 considerable levels of extinction. We conclude this because fossil Notostraca, attributed to

170 Triops and Lepidurus, have been found in modern day North and South America, Europe,

171 Africa and Antarctica, implying a global distribution by the early Jurassic (Gall \&

172 Grauvogel-Stamm 2005; Gand et al. 1997; Garrouste et al. 2009; Gore 1986; Haughton 1924;

173 Trusheim 1938) yet our LASER analysis shows a significant increase in the rate of

174 diversification of Notostraca about 73 Mya (Figure 2), close to the time of the K-Pg mass

175 extinction event. It is this second radiation that resulted in the current global distribution of

176 extant Triops and Lepidurus.

177 The almost synchronous radiation of Triops and Lepidurus (Figure 1) suggests that a common

178 factor may have triggered diversification of the two genera. The diversification of modern

179 birds - widely involved in dispersal in aquatic invertebrates (Green et al. 2005; van Leeuwen

180 et al. 2012) - coincided with the initiation of the notostracan radiation (Pacheco et al. 2011)

181 and may have facilitated the long distance dispersal and subsequent diversification of

182 Notostraca. Indeed, the geographical distribution of extant taxa (Figure 1) suggests several

183 instances of intercontinental dispersal. For example, the colonisation of North America from

184 Australia could have resulted from dispersal events during bird migration. Such long distance

185 dispersal and colonisation events might also have been facilitated by the flexible nature of

186 sexual systems found within Notostraca (Mathers et al. 2013). Indeed, the evolution of 
187 androdioecy - a sexual system where males and hermaphrodites coexist (Weeks, 2012;

188 Zierold et al. 2007, Zierold et al 2009) - from gonochorism appears to have favoured

189 postglacial recolonization in the species Triops cancriformis (Zierold et al 2009).

190 The concept of 'living fossils' has been a controversial one as it has often been interpreted to

191 imply a lack of evolutionary change, even against evidence of molecular evolutionary change

192 (Avise et al. 1994; Casane \& Laurenti 2013). Our divergence dating analysis has shown that

193 tadpole shrimps can be regarded as 'living fossils' only on the grounds of morphological

194 conservatism, not on the basis of limited diversification or relict status. Instead, throughout

195 their long evolutionary history, notostracans have undergone multiple global radiations and

196 high species turnover. Recent, time calibrated, phylogenetic analysis of other traditional

197 'living fossils’ such as cycads (Nagalingum et al. 2011), nautiloids (Wray et al. 1995)

198 horseshoe crabs (Obst et al. 2012) and monoplacophorans (Kano et al. 2012) have also

199 revealed that extant species are more recently diverged than suggested by fossil data alone.

200 We therefore caution against drawing conclusions on patterns of diversification based on

201 fossil data alone in groups where widespread morphological conservatism may obscure

202 rampant cryptic speciation. Furthermore, our results help clarify the term 'living fossils',

203 putting important questions into focus. Namely, is such morphological conservatism, in the

204 face of evolutionarily recent diversification and radiation, best accounted for by unchanging

205 selection or by developmental genetic constraints?

206 ACKNOWLEDGEMENTS

207 This work was part of T.C.M.’s Ph.D. We thank Chris Venditti for his help with the analyses,

208 and Dave Lunt and Steve Moss for bioinformatics support. Domino Joyce read and provided

209 constructive comments in a previous version of the manuscript. 
211

\section{REFERENCES}

Avise JC, Nelson WS, and Sugita H. 1994. A Speciational History of "Living Fossils": Molecular Evolutionary Patterns in Horseshoe Crabs. Evolution 48:1986-2001.

Barnard KH. 1929. A revision of the South African Branchiopoda Phyllopoda. Annals of the South African Museum 29:181 - 272.

Burbrink FT, and Pyron RA. 2010. How does ecological opportunity influence rates of speciation, extinction, and morphological fiversification in New World ratsnakes (tribe Lampropeltini)? Evolution 64:934-943.

Casane D, and Laurenti P. 2013. Why coelacanths are not 'living fossils'. BioEssays:n/a-n/a.

Darwin C. 1859. On the origins of species by means of natural selection. London: Murray.

Drummond AJ, Ho SYW, Phillips MJ, and Rambaut A. 2006. Relaxed Phylogenetics and Dating with Confidence. PLoS Biol 4:e88.

Drummond AJ, Suchard MA, Xie D, and Rambaut A. 2012. Bayesian phylogenetics with BEAUti and the BEAST 1.7. Molecular Biology and Evolution 29: 1969-1973.

Edgar RC. 2004. MUSCLE: multiple sequence alignment with high accuracy and high throughput. Nucleic Acids Research 32:1792-1797.

Eldredge N, and Gould SJ. 1972. Punctuated equilibria: an alternative to phyletic gradualism. Models in Paleobiology 82:115.

Fayers SR, and Trewin NH. 2002. A new crustacean from the Early Devonian Rhynie chert, Aberdeenshire, Scotland. Earth and Environmental Science Transactions of the Royal Society of Edinburgh 93:355-382.

Fedonkin MA, Simonetta A, and Ivantsov AY. 2007. New data on Kimberella, the Vendian mollusc-like organism (White Sea region, Russia): palaeoecological and evolutionary implications. Geological Society, London, Special Publications 286:157-179. 
234 Fryer G. 1988. Studies on the functional-morphology and biology of the Notostraca (Crustacea, Branchiopoda). Philosophical Transactions of the Royal Society of London Series B-Biological Sciences 321:27-142.

Gall J-C, and Grauvogel-Stamm L. 2005. The early Middle Triassic 'Grès àVoltzia’ Formation of eastern France: a model of environmental refugium. Paléontologie générale 4:569 560584.

240

Gand G, Garric J, and Lapeyrie J. 1997. Biocénoses à triopsidés (Crustacea, Branchiopoda) du Permien du bassin de Lodève (France). Geobios 30:673-700.

Garrouste R, Nel A, and Gand G. 2009. New fossil arthropods (Notostraca and Insecta: Syntonopterida) in the Continental Middle Permian of Provence (Bas-Argens Basin, France). Comptes Rendus Palevol 8:49-57.

245 Gore PJW. 1986. Triassic Notostracans in the Newark Supergroup, Culpeper Basin, Northern Virginia. Journal of Paleontology 60:1086-1096.

247 Green AJ, Sánchez MI, Amat F, Figuerola J, Hontoria F, Ruiz O, and Hortas F. 2005. Dispersal of Invasive and Native Brine Shrimps Artemia (Anostraca) via Waterbirds.

Harvey THP, Vélez MI, and Butterfield NJ. 2012. Exceptionally preserved crustaceans from western Canada reveal a cryptic Cambrian radiation. Proceedings of the National Academy of Sciences 109:1589-1594.

Haughton S. 1924. The fauna and stratigraphy of the Stormberg Series. Annals of the South African Museum 12:323-497.

Hegna, TA, and Dong REN. 2010. Two New “Notostracans”, Chenops gen. nov. and Jeholops gen. nov.(Crustacea: Branchiopoda:? Notostraca) from the Yixian Formation, Northeastern China. Acta Geologica Sinica-English Edition 84: 886-894. 
Ho SYW, and Phillips MJ. 2009. Accounting for Calibration Uncertainty in Phylogenetic Estimation of Evolutionary Divergence Times. Systematic Biology 58:367-380.

Kano Y, Kimura S, Kimura T, and Warén A. 2012. Living Monoplacophora: morphological conservatism or recent diversification? Zoologica Scripta 41:471-488.

King JL, and Hanner R. 1998. Cryptic species in a "Living Fossil" lineage: Taxonomic and phylogenetic relationships within the genus Lepidurus (Crustacea : Notostraca) in North America. Molecular Phylogenetics and Evolution 10:23-36.

Korn M, Green AJ, Machado M, Garcia-de-Lomas J, Cristo M, da Fonseca LC, Frisch D, Perez-Bote JL, and Hundsdoerfer AK. 2010. Phylogeny, molecular ecology and taxonomy of southern Iberian lineages of Triops mauritanicus (Crustacea: Notostraca). Organisms Diversity and Evolution 10:409-440.

Korn M, and Hundsdoerfer AK. 2006. Evidence for cryptic species in the tadpole shrimp Triops granarius (Lucas, 1864) (Crustacea : Notostraca). Zootaxa 1257:57-68.

Kotov AA, and Taylor DJ. 2011. Mesozoic fossils (> 145 Mya) suggest the antiquity of the subgenera of Daphnia and their coevolution with chaoborid predators. BMC Evolutionary Biology 11:129.

Lanfear R, Calcott B, Ho SYW, and Guindon S. 2012. PartitionFinder: Combined Selection of Partitioning Schemes and Substitution Models for Phylogenetic Analyses. Molecular Biology and Evolution 29:1695-1701.

Macdonald KS, Sallenave R, and Cowley DE. 2011. Morphological and genetic variation in Triops (Branchiopoda: Notostraca) from ephemeral waters of the Northern Chihuahuan desert of North America. Journal of Crustacean Biology 31:468-484.

Mantovani B, Cesari M, Luchetti A, and Scanabissi F. 2008. Mitochondrial and nuclear DNA variability in the living fossil Triops cancriformis (Bosc, 1801) (Crustacea, Branchiopoda, Notostraca). Heredity 100:496-505. 
Mathers TC, Hammond RL, Jenner RA, Zierold T, Hänfling B, and Gómez A. 2013. High lability of sexual system over 250 million years of evolution in morphologically conservative tadpole shrimps. BMC Evolutionary Biology 13:30.

Nagalingum NS, Marshall CR, Quental TB, Rai HS, Little DP, and Mathews S. 2011. Recent Synchronous Radiation of a Living Fossil. Science 334:796-799.

Obst M, Faurby S, Bussarawit S, and Funch P. 2012. Molecular phylogeny of extant horseshoe crabs (Xiphosura, Limulidae) indicates Paleogene diversification of Asian species. Molecular Phylogenetics and Evolution 62:21-26.

Olesen J. 2009. Phylogeny of Branchiopoda (Crustacea)—Character evolution and contribution of uniquely preserved fossils. Arthropod Systematics and Phylogeny 67: 3-39.

Pacheco MA, Battistuzzi FU, Lentino M, Aguilar R, Kumar S, and Escalante AA. 2011. Evolution of modern birds revealed by Mitogenomics: timing the radiation and origin of major orders. Molecular Biology and Evolution 28:1927-1942.

Phillimore AB, and Price TD. 2008. Density-dependent cladogenesis in birds. PLoS biology 6:e71.

Pons J, Barraclough TG, Gomez-Zurita J, Cardoso A, Duran DP, Hazell S, Kamoun S, Sumlin WD, and Vogler AP. 2006. Sequence-based species delimitation for the DNA taxonomy of undescribed insects. Systematic Biology 55:595-609.

Rabosky DL. 2006. LASER: a maximum likelihood toolkit for detecting temporal shifts in diversification rates from molecular phylogenies. Evol Bioinform Online 2:273-276.

Rambaut A, and Drummond A. 2007. Tracer v1. 4 [upated to v1. 5].

Regier JC, Shultz JW, Zwick A, Hussey A, Ball B, Wetzer R, Martin JW, and Cunningham CW. 2010. Arthropod relationships revealed by phylogenomic analysis of nuclear protein-coding sequences. Nature 463:1079-U1098. 
Reznick DN, and Ricklefs RE. 2009. Darwin's bridge between microevolution and macroevolution. Nature 457:837-842.

Rhodes FHT. 1983. Gradualism, punctuated equilibrium and the Origin of Species. Nature 305:269-272.

Rogers DC. 2001. Revision of the nearctic Lepidurus (Notostraca). Journal of Crustacean Biology 21:991-1006.

Ronquist F, Teslenko M, van der Mark P, Ayres DL, Darling A, Höhna S, Larget B, Liu L, Suchard MA, and Huelsenbeck JP. 2012. MrBayes 3.2: Efficient Bayesian Phylogenetic Inference and Model Choice Across a Large Model Space. Systematic Biology 61:539-542.

Scotese CR. 2001. Atlas of earth history: University of Texas at Arlington. Department of Geology. PALEOMAP Project.

Stamatakis A. 2006. RAxML-VI-HPC: Maximum likelihood-based phylogenetic analyses with thousands of taxa and mixed models. Bioinformatics 22:2688-2690.

Tamura K, Peterson D, Peterson N, Stecher G, Nei M, and Kumar S. 2011. MEGA5: Molecular evolutionary genetics analysis using maximum likelihood, evolutionary distance, and maximum parsimony methods. Molecular Biology and Evolution 28:2731-2739.

Trusheim F. 1938. Triopsiden (Crust. Phyll.) aus dem Keuper Frankens. Paläontologische Zeitschrift 19:198-216.

van Leeuwen CHA, van der Velde G, van Groenendael JM, and Klaassen M. 2012. Gut travellers: internal dispersal of aquatic organisms by waterfowl. Journal of Biogeography 39:2031-2040. 
331 Vanschoenwinkel B, Pinceel T, Vanhove MPM, Denis C, Jocque M, Timms BV, and Brendonck L. 2012. Toward a Global Phylogeny of the "Living Fossil" Crustacean Order of the Notostraca. Plos One 7:e34998.

von Reumont BM, Jenner RA, Wills MA, Dell’Ampio E, Pass G, Ebersberger I, Meyer B, Koenemann S, Iliffe TM, Stamatakis A et al. 2012. Pancrustacean Phylogeny in the Light of New Phylogenomic Data: Support for Remipedia as the Possible Sister Group of Hexapoda. Molecular Biology and Evolution 29:1031-1045.

338 Waloßek D. 1995. The Upper Cambrian Rehbachiella, its larval development, morphology and significance for the phylogeny of Branchiopoda and Crustacea. Hydrobiologia 298:1-13.

341 Weeks SC. 2012. The Role of Androdioecy and Gynodioecy in Mediating Evolutionary Transitions Between Dioecy and Hermaphroditism in the Animalia. Evolution. 66: 3670-3686.

344 Womack T, Slater BJ, Stevens LG, Anderson LI, and Hilton J. 2012. First cladoceran fossils from the Carboniferous: Palaeoenvironmental and evolutionary implications. Palaeogeography, Palaeoclimatology, Palaeoecology 344-345:39-48.

347 Wray CG, Landman NH, Saunders WB, and Bonacum J. 1995. Genetic divergence and 348

Zierold T, Hanfling B, and Gómez A. 2007. Recent evolution of alternative reproductive 350 modes in the 'living fossil' Triops cancriformis. BMC evolutionary biology 7: 161.

Zierold T, Montero-Pau J, Hänfling B, and Gómez A. 2009. Sex ratio, reproductive mode and 352 genetic diversity in Triops cancriformis. Freshwater Biology 54: 1392-1405. 


\section{Table $\mathbf{1}_{\text {(on next page) }}$}

Fossils used to calibrate divergence time analysis in BEAST.

Age constraints are treated as hard bounds unless otherwise stated. Node numbers indicate phylogenetic placement of fossil calibrations in Figure 1. 


\begin{tabular}{|c|c|c|c|c|c|}
\hline Node & Fossil taxa & Geological period & $\begin{array}{l}\text { Minimum age } \\
\text { (Mya) }\end{array}$ & $\begin{array}{l}\text { Maximum age } \\
\text { (Mya) }\end{array}$ & Reference \\
\hline 1 & Oldest Bilateria eg. Kimberella & Ediacaran & - & 558 & Fedonkin et al. 2007 \\
\hline 1 & Rehbachiella & Upper Cambrian & - & 500 (soft max) & $\underline{\text { Waloßek } 1995}$ \\
\hline 1 & Undescribed añostracan & Base Ordovician & 488 & - & Harvey et al. 2012 \\
\hline 2 & 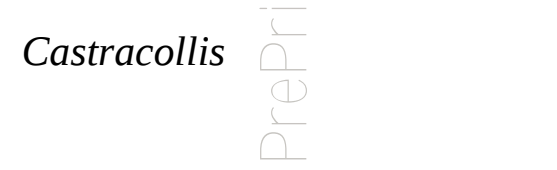 & Pragian, Early Devonian & 410 & - & $\begin{array}{l}\text { Fayers \& Trewin } \\
\underline{2002}\end{array}$ \\
\hline 3 & Ebullitiocaris elatus & Carboniferous & 300 & - & $\underline{\text { Womack et al. } 2012}$ \\
\hline 4 & Daphnia and Ctenodaphnia sp. & Jurassic / Cretaceous & 145 & - & $\underline{\text { Kotov \& Taylor } 2011}$ \\
\hline
\end{tabular}




\section{Figure 1}

Time calibrated phylogeny of 38 notostracan species and seven branchiopod outgroups.

Numbers at nodes correspond to the fossil calibrations given in Table 1. Nodes with black circles have ML Bootstrap support values greater than 70 and posterior probabilities greater than 95 from the RAxML and MrBayes analyses respectively. Error bars show the 95\% confidence intervals of divergence times. Colour coded squares show the known geographic distribution of each species.

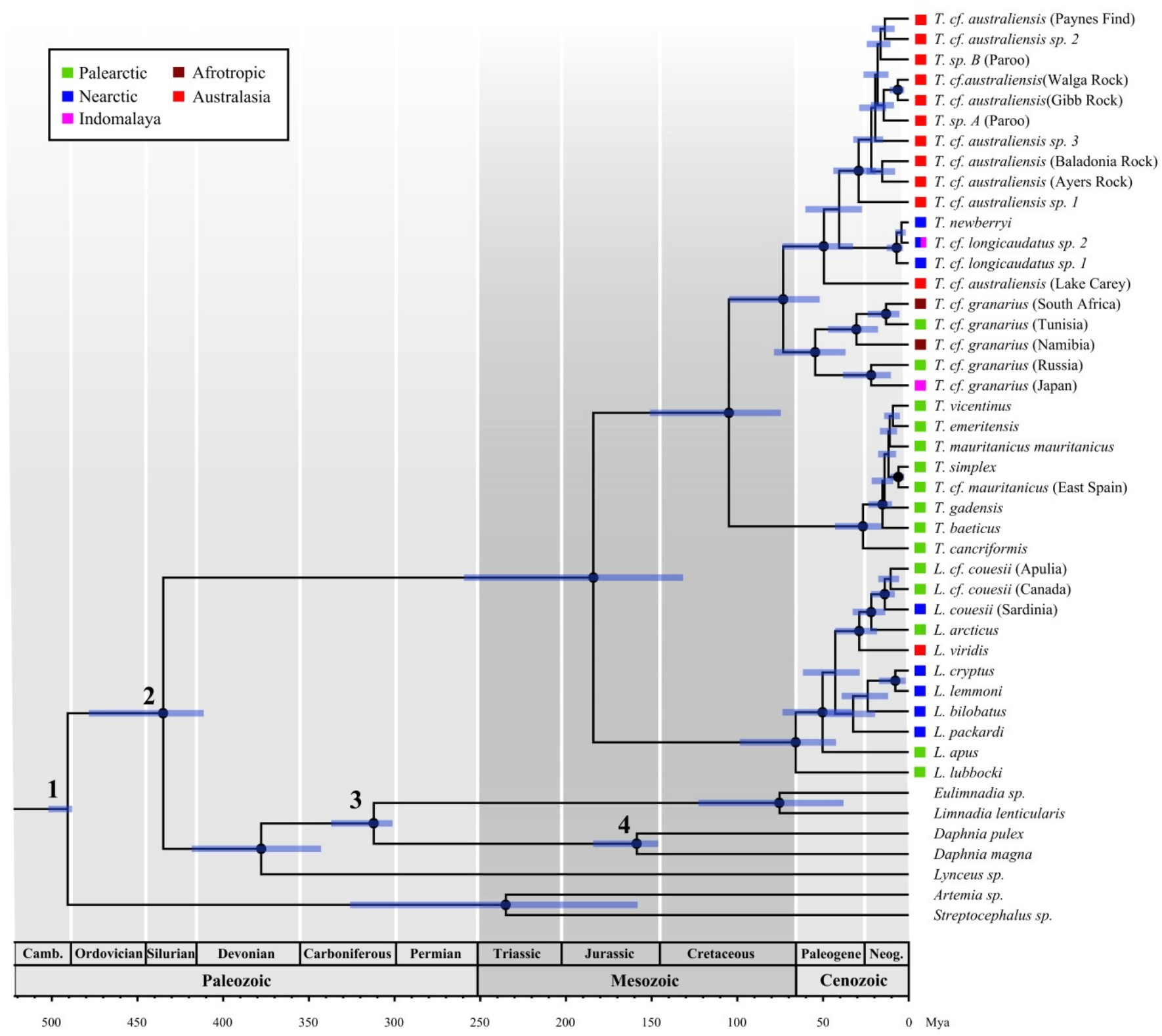




\section{Figure 2}

Diversification of Notostraca through time.

Arrows indicate the timing and direction of shifts in rate of diversification inferred by LASER. $\mathrm{N}$ is the number of species. The best fit ML model of diversification identified three distinct rates of diversification during the evolutionary history of Notostraca with an increase in speciation rate 73 Mya followed by a decrease 6 Mya. 


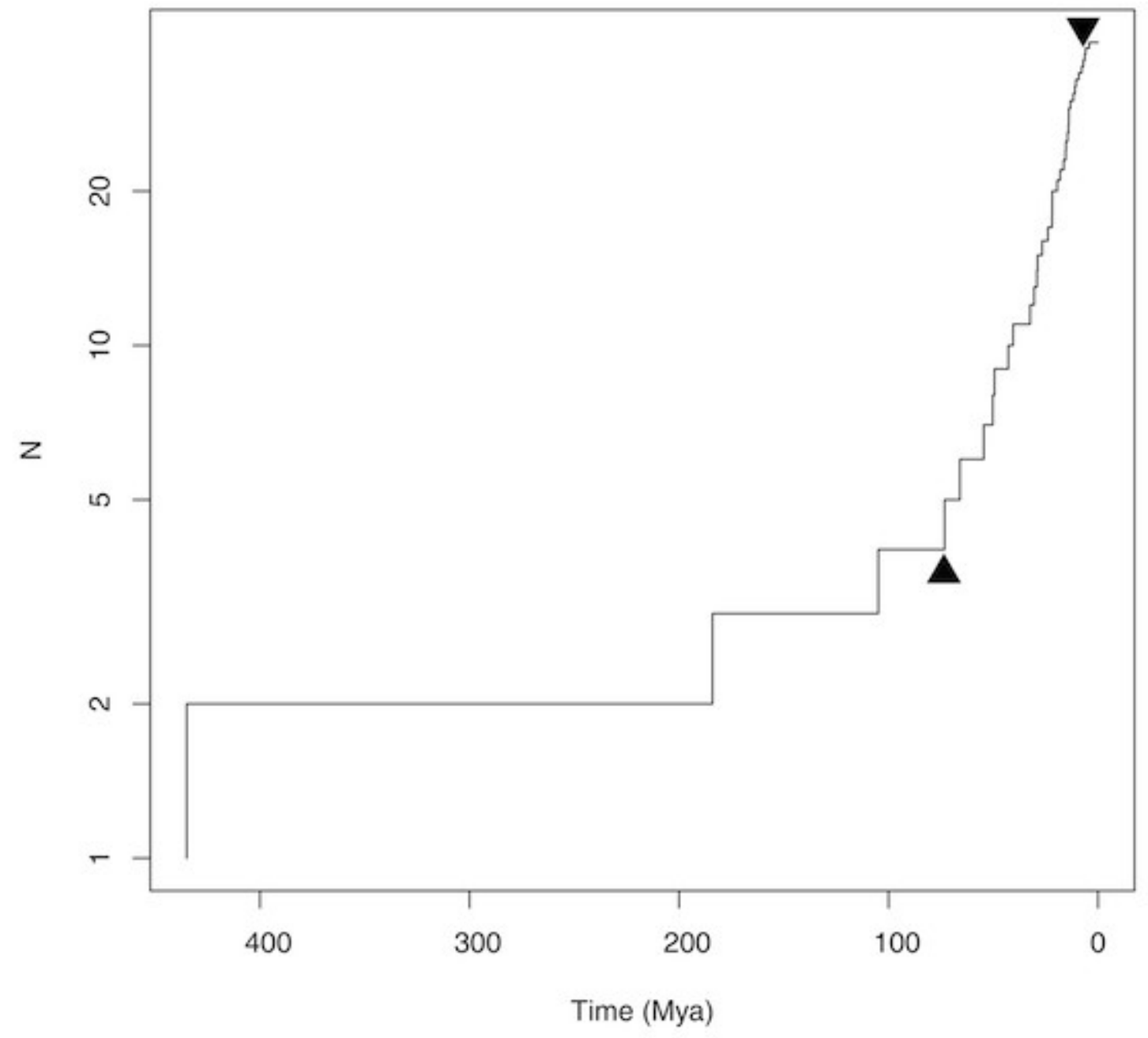

